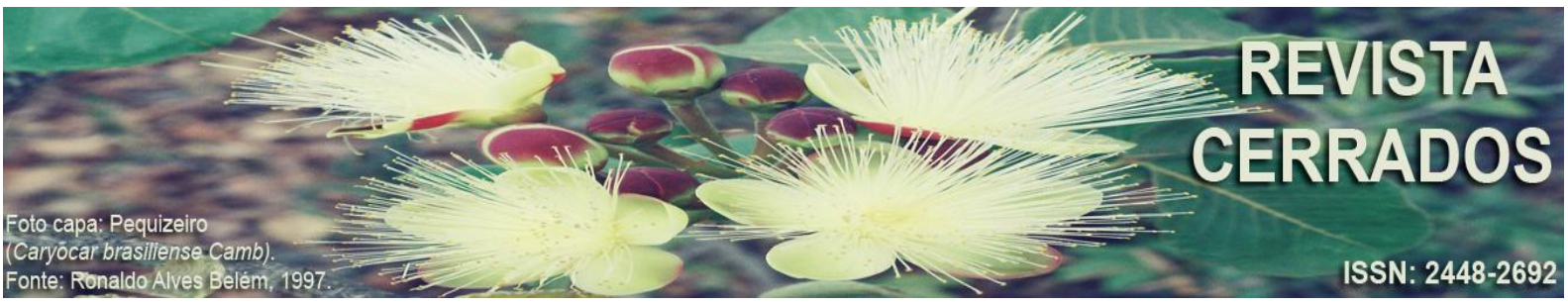

\title{
A APLICAÇÃO DO PROGRAMA NACIONAL DE PRODUÇÃO E USO DO BIODIESEL NA AGRICULTURA CAMPONESA EM ÁREAS DE REFORMA AGRÁRIA
}

\section{THE APPLICATION OF THE NATIONAL PROGRAM FOR THE PRODUCTION AND USE OF BIODIESEL IN FAMILY AGRICULTURE IN AREAS OF THE AGRARIAN REFORM}

\section{LA APLICACIÓN DEL PROGRAMA NACIONAL DE PRODUCCIÓN Y USO DEL BIODIESEL EN LA AGRICULTURA FAMILIAR EN ÁREAS DE REFORMA AGRARIA}

\author{
Cássia Betânia Rodrigues dos Santos \\ Universidade de Brasília - UnB \\ E-mail: <cassiageoterra@hotmail.com>.
}

\begin{abstract}
Resumo
Este ensaio é resultado do aproveitamento da disciplina Políticas Públicas: Território e Desenvolvimento do Programa de Pós-graduação em Meio Ambiente e Desenvolvimento Rural da Universidade de Brasília que foi ministrada no segundo semestre de 2015. O ensaio tem por objetivo analisar o Programa Nacional de Produção e Uso de Biodiesel (PNPB) lançado em 2003 pelo governo federal e a sua articulação com a política federal de Reforma Agrária. O PNPB foi configurado como uma política setorial que se baseia no pilar ambiental, na geração de renda para uma população desfavorecida e criação de demanda energética. Sabendo que essa articulação existente entre o PNPB e a Reforma Agrária pode ser de caráter positivo ou negativamente. É importante estar considerando alguns aspectos, tais como os interesses/preferências que influenciam na definição e no estabelecimento de uma determinada política, deve também considerar a visão holística, na qual o todo se sobressai em relação as partes, e que indivíduos, instituições, ideologias e interesses são considerados neste processo. A metodologia empregada para realização desse trabalho foi a pesquisa bibliográfica e documental, não havendo a pesquisa de campo.
\end{abstract}

Palavras-chave: Estado; PNPB; Reforma Agrária. 
SANTOS, C. B. R.

A aplicação do Programa Nacional de Produção e Uso do Biodiesel na Agricultura Camponesa em Áreas de Reforma Agrária

\begin{abstract}
This essay is the result of the use of the discipline Public Policies: Territory and Development of the Postgraduate Program in Environment and Rural Development of the University of Brasília, which was given in the second half of 2015. The objective of this essay is to analyze the National Production Program and Use of Biodiesel (PNPB) launched in 2003 by the federal government and its articulation with the federal policy of Agrarian Reform. The PNPB was configured as a sectoral policy based on the environmental pillar, generating income for a disadvantaged population and creating energy demand. Knowing that this articulation between the PNPB and the Agrarian Reform can be of a positive or negative character. It is important to be considering some aspects, such as interests / preferences that influence the definition and establishment of a particular policy, should also consider the holistic vision, in which the whole stands out in relation to the parts, and which individuals, institutions, ideologies and interests are considered in this process. The methodology used to carry out this work was the bibliographical and documentary research, with no field research.
\end{abstract}

Keywords: State; PNPB; Land Reform.

\title{
Resumen
}

Este es el resultado del uso de las políticas públicas: Territorio y desarrollo del programa de formación en el campo de desarrollo y desarrollo de la Universidad de Brasilia, que se dio en el segundo semestre de 2015. El objetivo de este ensayo es analizar el Instituto Nacional de Producción y Uso de Biodiesel (PNPB) iniciado en 2003 por el gobierno federal y su articulación con la política federal de Agrarian Reform. El PNPB se configuró a la política sectorial basada en el pilar de los pilares, la renta de los ingresos para la pericia de la población y la demanda de demanda de energía. Saber que esta articulación entre el PNPB y el Agrarian Reform puede ser un positivo o negativo. Es importante tener en cuenta algunos aspectos, como los intereses / las preferencias que influyen en la definición y establecimiento de una política concreta, también debe considerar la visión holística, las ideologías y los intereses se consideran en este proceso. El método utilizado para llevar a cabo este trabajo fue la bibliografía y la documentación documental, con en el campo de investigación.

Palabras clave: Estado; PNPB; la reforma Agrária.

\section{INTRODUÇÃO}

A terra no Brasil ainda é um meio de produção que carrega marcas de profundas desigualdades, e essa realidade não é de hoje, corresponde a época ainda da colonização brasileira. Portanto falar de concentração de terras é recorrer a história para entender o presente. Muitos camponeses, infelizmente não detém o meio de produção terra, que está concentrada nas mãos do setor empresarial de escala é da oligarquia (FERNANDES; WECH; 
SANTOS, C. B. R.

A aplicação do Programa Nacional de Produção e Uso do Biodiesel na Agricultura Camponesa em Áreas de Reforma Agrária

GONÇALVES, 2013). E por essa razão existiram e ainda existem muitos conflitos no campo. De acordo com informações divulgadas por Albuquerque (2017) somente em 2000 foram registrados 660 conflitos no Brasil com 21 mortes e em 2015 foram registrados 1217 conflitos com 50 mortes e em 2016 foram registrados 61 o número de mortes. Os movimentos sociais, portanto, reivindicam do Estado, através de manifestações, da luta pela terra, soluções para esse velho problema da concentração fundiária.

É fato que a realidade do Brasil colonial mudou bastante em relação ao que temos agora. A desigualdade ainda persiste, mas muitos direitos antes sonegados, hoje são reconhecidos seja através de Leis, seja através de políticas públicas, embora muitas fiquem no estágio do discurso e do papel ou não correspondam à realidade daqueles para quem são destinadas.

O foco desse trabalho é a análise de duas políticas públicas em particular; considerando que as políticas públicas, podem ser definidas como o "Estado em ação", (MOLINA, 2012) o Estado intervém para atender as necessidades da população.

Escolhemos, a política de Reforma Agrária e o Programa Nacional de Produção e Uso do Biodiesel ${ }^{1}$. Duas políticas que a priori, pretendem reconhecer e fortalecer os direitos da agricultura camponesa tanto a terra como o auxílio ao uso desta. São duas políticas que carregam importantes funções para a classe camponesa, uma vez que ambas devem ou deveriam resolver necessidades prioritárias desses sujeitos.

Mas, como já foi abordado, no pano de fundo podemos observar um quadro de aplicação bastante diferente do que está circunscrita nos documentos das leis, políticas, programas. Alguns desses instrumentos aparecem descontextualizados da realidade dos sujeitos ou mantem engavetados. De acordo com Fernandes, Wech e Gonçalves (2013, p. 70) "tem ocorrido o avanço das políticas neoliberais e que essas tem aniquilado várias conquistas, aumentando a subordinação das classes populares através de políticas compensatórias e de controle social”. Ou ainda é como a política de Reforma Agrária, que tem sido um processo que não se caracteriza enquanto Reforma Agrária. Na verdade, falar de Reforma Agrária é lembrar de uma dívida histórica ao povo brasileiro.

\footnotetext{
1 "É um programa interministerial do Governo Federal, criado em 2004, que objetiva a implementação de forma sustentável, tanto técnica, como econômica, da produção e uso do biodiesel, com enfoque na inclusão social e no desenvolvimento regional, via geração de emprego e renda". (MDA, 2017)
} 
SANTOS, C. B. R.

A aplicação do Programa Nacional de Produção e Uso do Biodiesel na Agricultura Camponesa em Áreas de

Reforma Agrária

Desde 1988, os camponeses organizados conseguiram obter importantes conquistas. Primeiro com a Constituição, posteriormente com a criação do Programa Nacional da Agricultura Familiar (Pronaf), em 1996, a criação do Ministério do Desenvolvimento Agrário (MDA) em 2003, o reconhecimento do direito à aposentadoria rural no mesmo ano e em 2006, a promulgação da Lei da Agricultura Familiar.

É fato ainda que se a distribuição de terras não ocorria em governos anteriores, pior será com o atual governo de Temer, que tem se mostrado contrário as perspectivas da classe trabalhadora e principalmente em se tratando dos camponeses. Os vários cortes sancionados no governo Temer têm as políticas, programas voltados a questão agrária.

Assim, as poucas famílias que ainda recebem a posse da terra também teriam o direito de receber meios para desenvolver sua produção: sementes, implantação de irrigação e eletrificação, financiamentos, infraestrutura, assistência social e consultoria, o que atualmente se torna mais difícil de ser conseguido por essas famílias camponesas. (POLINSK; PINTO, 2009).

Entretanto, há um claro direcionamento das políticas públicas para o agronegócio. Portanto, a elaboração de políticas que acreditam que o desenvolvimento da agricultura familiar pode se dar através de um padrão tecnológico próximo ao do agronegócio e que a única diferença entre os dois modelos seria a escala de produção (JÚNIA, 2016, p. 01).

O PNPB é uma das políticas que deveria ter tido essa função segundo o Estado de dar assistência, aumentando a renda do sujeito camponês. Na verdade, o objetivo desse programa é de responder ao apelo ambiental e econômico, quando se reforça o uso de biomassa como uma fonte alternativa de energia, com objetivo de substituir o petróleo. Além de diminuir os danos ambientais com o uso do petróleo, também pretendeu incluir o camponês nesse processo, ao lhes possibilitar trabalho e renda no campo a partir da plantação de oleaginosas, assim evitar o êxodo rural também foi um dos propósitos pretendido por esse programa. Ou seja, os próprios camponeses passaram a ser um dos grandes responsáveis para produção de energia limpa.

Como estratégia de marketing, o agronegócio vem incorporando no seu discurso a sustentabilidade e justiça social. Mas esse discurso do agronegócio não se sustenta, há um processo progressivo de precarização dos direitos e da capacidade de apropriação dos agricultores e suas famílias, cada vez mais pressionados por essas grandes empresas e fazendeiros estimulados por esse conjunto de políticas (JÚNIA, 2016, p. 01). 
SANTOS, C. B. R.

A aplicação do Programa Nacional de Produção e Uso do Biodiesel na Agricultura Camponesa em Áreas de

Reforma Agrária

O Estado, ao mesmo tempo que dá, também retira, e isso acontece porque segundo Felício e Fernandes "a luta pela terra está assentada no processo contraditório de desenvolvimento do capital que, ao mesmo tempo em que expropria, abre possibilidade histórica do retorno a terra" (2013, p. 53). E em consequência subordinação da terra e do trabalho familiar.

O objetivo do ensaio é analisar como o PNPB se articula com a política de Reforma Agrária, como o PNPB interferiu no campo brasileiro e assim corroborar ou refutar a ideia de que as duas políticas possuam ou não uma relação complementar e significativa para o fortalecimento da agricultura camponesa. Portanto, a partir de uma relação existente entre as políticas públicas que as propostas deverão ganhar sentido e ser materializadas no território daqueles sujeitos.

\section{Estado e política pública}

Para iniciar essa discussão podemos refletir primeiramente na seguinte frase de Bastiat a propósito do Estado

Tudo o que dele sabemos é que se trata de um personagem misterioso e, sem sombra de dúvida, o mais solicitado, o mais atormentado, o mais ocupado, o mais aconselhado, o mais acusado, o mais invocado e o mais provocado que exista no mundo (s/d. p.02)

De modo geral podemos dizer que o papel do Estado, é de implementar ações para atender a demanda da sociedade. Assim as decisões tomadas, as escolhas feitas, os caminhos de implementação traçados e os modelos de avaliação aplicados em relação a uma estratégia de intervenção governamental qualquer, são de responsabilidade do Estado. Essas ações tomam a forma de políticas públicas. Cada política pública tem um objetivo diferente, e os objetivos dependem dos atores a quem se destina a política, do problema, e do seu momento histórico.

Em outras palavras o Estado, através de um governo, implanta programas de ações voltadas a um público específico da sociedade. E é nessa oportunidade que podemos colocar que a partir do governo, que o Estado brasileiro desde muito tempo tem sido corrompido e, portanto, favorecido ao capital. Quanto a posição do Estado, Fernandes, Wech e Gonçalves (2013, p. 69-70) nos ajuda a afirmar que 
SANTOS, C. B. R.

A aplicação do Programa Nacional de Produção e Uso do Biodiesel na Agricultura Camponesa em Áreas de

Reforma Agrária

O governo toma posições a favor do agronegócio, devido a predominância do paradigma do capitalismo agrário nos ministérios e a pressão agressiva do poderoso setor da agricultura convencional. Por outro lado, o Estado cria e implanta políticas para o reconhecimento e desenvolvimento dos territórios camponeses somente sob pressão popular.

Assim, muito do que já foi conquistado pelas classes populares seja ela leis, políticas públicas, não se deve a boa vontade do Estado, se deve a luta, ao derramamento de sangue de muitos que já sonharam um dia com o reconhecimento de seus direitos. Gramsci, nos ajuda a entender o Estado ao afirmar que o mesmo não é neutro, mas também "não é mero instrumento de dominação, o Estado é resultado da condensação de uma relação de forças sociais, o resultado contraditório das lutas de classes, em que se manifestam interesses contraditórios".

O Estado brasileiro tem hoje uma classe especifica: a burguesia. E o poder da burguesia no Estado tem se dado especificamente pela sociedade civil que engloba esferas capazes de influenciar na aceitação, convencimento e conformismo, a igreja, escola e a mídia. A igreja, escola e a mídia são exemplos mais claros de organismos sociais que apresentam ideologias construídas no exercício da dominação.

No Estado brasileiro dominou e domina ainda a negação dos direitos aos sujeitos do campo incluindo principalmente o direito do acesso à terra. De acordo com Santos o

Estado capitalista está permanentemente desafiado a, por todos os seus meios, impregnar a sociedade da ideologia dominante; a classe trabalhadora organizada na sociedade civil caberá, por seus meios desmontá-la (2009, p. 19).

O objetivo do Estado é de assegurar a ordem da sociedade para poder provocar com mais e mais intensidade a ampliação/atuação do capital. E como coloca Santos (2009) isso é sentido de maneiras diferentes dependendo do nivel de desenvolvimento da sociedade civil e de suas experiencias históricas. Portanto, os sujeitos do campo se organizam na sociedade civil e tem atuado ou deve atuar no sentido da contra-hegemonia, afim de fortalecer seus interesses dentro do Estado.

Assim, foi a partir dessa força da classe trabalhadora do campo, que a maioria das políticas públicas de agricultura camponesa e desenvolvimento rural foram implementadas, mas da mesma forma tiveram políticas públicas construídas para classe trabalhadora e em especial os camponeses, mas que não foram com os camponeses. 


\section{As políticas públicas}

Nos Estados Unidos, os estudos sobre políticas públicas iniciaram na década de 1950, denominada de Policy Science, já na Europa as preocupações com estudos sobre políticas públicas tomaram mais importância a partir da década de 1970, (TREVISAN; VAN BELLEN, 2008). Segundo esses autores, no Brasil o estudo sobre políticas públicas é ainda mais recente recaindo sobre à análise das estruturas e instituições ou à caracterização dos processos de negociação das políticas setoriais específicas.

De modo geral as políticas públicas podem ser de caráter regional, territorial ou temáticas. Hoje é mais comum termos políticas públicas que são pensadas através de setores, subsetores ou temas. É bem recente nas políticas brasileiras o caráter territorial. A política territorial rural no Brasil serve de modelo para muitos outros países respectivamente no continente americano, porém, no Brasil a aplicação dessas políticas territoriais enfrenta muitas dificuldades.

É interessante examinar como a abordagem territorial se consolidou no escopo das políticas públicas. As interpretações do rural brasileiro sofreram influência do contexto europeu. Assim, a elaboração da ideia de desenvolvimento rural passou a se orientar nas transformações do mundo rural particularmente o europeu que vinha sofrendo mudanças na sua dinâmica devido à grande ligação que houve com o urbano por causa do capitalismo avançado que estava sendo vivenciado.

Contudo, estudiosos brasileiros acabaram sendo influenciados também pelas problematizações que apareciam no contexto rural europeu. Os estudiosos, acreditavam então que o capitalismo que modificou o rural da Europa, seria natural e inevitável no Brasil. Assim, Abramovay importante estudioso da época, compara os agricultores dos países mais desenvolvidos com agricultores de países emergentes como o Brasil. Claramente temos duas realidades totalmente distintas, uma vez que os agricultores que viveram nos países onde o capitalismo chegou em seu ápice, também integraram ao mercado e se perpetuaram como um segmento social importante, Porto (2015).

Deste modo, Abramovay acreditou que o camponês se tornaria um agricultor familiar, já que isso acontecia na Europa. Então ele propõe a criação dessa nova categoria para tratar da transformação que haveria com o homem do campo brasileiro. Ele acreditava 
SANTOS, C. B. R.

A aplicação do Programa Nacional de Produção e Uso do Biodiesel na Agricultura Camponesa em Áreas de Reforma Agrária

que era deixar de ser camponês para ter uma profissão, chamada de agricultor camponesa, onde não haveria laços comunitários, o que importava agora era a reprodução material.

Vigora então a concepção do rural contemporâneo onde a academia, os atores sociais e o próprio Estado pensa, trabalha em políticas públicas destinadas a um rural agora diferente, o rural contemporâneo do agricultor familiar. Só que tudo isso gera grande polêmica e autores como Alentejano, Fernandes, foram importantes para provocar um contra debate.

O termo agricultor familiar influenciaria diretamente nas políticas públicas criadas para atender o quadro rural que vigorava no Brasil, e esse quadro refere ao novo padrão de política econômica neoliberal adotado no Brasil nos anos 1990 (Porto 2015). Assim autores como Alentejano (2000), Fernandes (2010), e Bastos (2006) também ajudaram a fazer duras críticas inclusive sobre a origem da categoria agricultor familiar, afim de alertar o que estava realmente acontecendo. $\mathrm{O}$ objetivo era a incorporação das diretrizes neoliberais para as políticas de intervenção sobre o rural. Segundo Porto (2015) a categoria agricultor familiar trouxe problemas teóricos, uma vez que reduziria o sujeito do campo a um mero produto de ação do Estado, ou seja, era negar a capacidade de assimilação, apropriação e manutenção da história e das tradições camponesas. Assim agricultor familiar é uma construção social que parte principalmente de interesses do Estado. Contudo, a agricultura camponesa teve um importante papel para a definição de políticas públicas ligados ao desenvolvimento territorial rural.

Dessa forma, concluímos que a utilização do termo agricultor familiar seja em políticas públicas, seja na própria academia, tem intenções de reduzir o sujeito camponês, negando sua identidade, sua luta. Agricultor familiar é utilizado em políticas públicas para trazer um novo sujeito do campo, ou seja, na transformação do sujeito camponês.

A saber todo camponês é um agricultor familiar, embora alguns autores não considerem que o contrário também seja verdadeiro, como é o caso de Romeiro (2002). A diferenciação entre agricultor familiar e camponês é mais uma tentativa de fragmentação e cooptação. Quando utilizamos o termo camponês, estamos ultrapassando as condições econômicas produtivas, assim toda a dinâmica geográfica, social, política e cultural que acontece nesse campo são determinantes para um modo sustentável de desenvolvimento rural da agricultura camponesa. 
SANTOS, C. B. R.

A aplicação do Programa Nacional de Produção e Uso do Biodiesel na Agricultura Camponesa em Áreas de Reforma Agrária

Segundo Fernandes (2008) a construção teórica da agricultura familiar tem construído a compreensão e a percepção que o camponês representa o velho, o arcaico e o atraso, enquanto o agricultor familiar representa o novo, o moderno, o progresso. Evidente que os custos políticos dessas formas de entendimento são altíssimos para os movimentos camponeses.

Enquanto camponesa, militante, e na luta com o movimento dos trabalhadores rurais sem tem que este trabalho a todo momento faz referência ao termo camponês para se enaltecer uma luta que tem futuro.

\section{O Programa Nacional de Produção e Uso de Biodiesel (PNPB)}

A priori, o Biodiesel é um combustível advindo da biomassa, suas características são de ser renovável e biodegradável, e ainda com capacidade de substituir o óleo diesel, (FERREIRA, et al, 2008). Após a Segunda Guerra Mundial inúmeras crises do petróleo surgiram e assim houve uma preocupação muito grande da dependência mundial do petróleo. Dessa forma descobrir uma nova fonte de energia passou a ser importante, uma vez que no continente asiático, onde mais encontra petróleo é onde também mais ocorre conflitos.

Em outras palavras, a produção de energias limpas e renováveis tornam importantes a partir do momento que sabemos que o petróleo é um recurso esgotável e que além desse fator também emite muitos gases poluentes na atmosfera e provoca poluição do meio ambiente a partir dos produtos que com ele também são fabricados.

No Brasil os primeiros estudos sobre biodiesel iniciaram na Universidade Federal do Ceará, na década de 1970 conseguindo a transformação do óleo vegetal em biodiesel a partir do processo de transesterificação, Dalenogare, (2011). Antes mesmo de surgir o primeiro programa que estimularia a produção de biodiesel teve a criação de projetos na década de 1980, como o PROOLEO e o OVEG, mas foram inviáveis pois o petróleo abaixou o preço e a produção de biodiesel demandava altos custos. Esses dois programas, embora tenha se tornado somente projetos, eles tiveram um papel fundamental para o desenvolvimento das próximas iniciativas de políticas públicas com objetivo a produção de biodiesel.

A década de 1990 volta o preço elevado do petróleo e claramente a emergência de alternativas que fosse possível amenizar a crise econômica e ambiental, portanto nova 
SANTOS, C. B. R.

A aplicação do Programa Nacional de Produção e Uso do Biodiesel na Agricultura Camponesa em Áreas de Reforma Agrária

oportunidade surge para a retomada de onde haviam parado na produção de biodiesel por óleo vegetal. O primeiro programa que teve por objetivo estimular a produção de biodiesel ocorreu em 2002, este era o Programa Brasileiro de Biocombustíveis (Probiodiesel). O Probiodiesel estimulava principalmente a produção de soja pelos empresários, na região Centro-Oeste do país. Contudo em 2003 a 2005 ocorreu uma reformulação dessa política passando a ser o Programa Nacional de Produção e Uso do Biodiesel (PNPB), de caráter interministerial, ou seja, com participação de vários órgãos ministeriais e governamentais tendo como a principal mudança dentro desse novo programa a inserção dos agricultores camponeses com o enfoque aos agricultores da região Nordeste do país estimulando a produção de oleaginosas.

Assim o objetivo era trazer às famílias assentadas a possibilidade de estar cultivando oleaginosas como fonte de energia limpa, proporcionando renda e emprego as famílias. Em outras palavras, o PNPB objetivou a implementação de forma sustentável, tanto técnica, como econômica, da produção e uso do biodiesel, com preocupação na inclusão social, no desenvolvimento regional, a partir da geração de emprego e renda.

As oleaginosas são plantas como girassol, mamona, soja e o dendê que foi fazendo parte da agricultura cultivada pelos camponeses. Como cada região do país tem uma característica de solo diferente, a soja, por exemplo, foi muito cultivada pelos pequenos produtores particularmente no bioma cerrado. Os assentados enviaram as oleaginosas produzidas para as empresas. Ou seja, as empresas seriam as responsáveis por estar comprando a produção. Empresas ou usinas adquiriram o Selo Combustível Social, que é um certificado fornecido pelo governo às unidades produtoras que atendem aos requisitos de inclusão da agricultura camponesa na cadeia produtiva do biodiesel. Assim, essas empresas com o Selo Combustível Social teriam a partir do MDA desconto nos impostos.

Muitas famílias assentadas faziam bem antes do PNPB e ainda fazem o arrendamento da terra para o plantio principalmente da soja, então essa política só fortaleceu essa prática, mas seguindo uma dinâmica um pouco diferente. Logo, o PNPB englobou "agricultores camponeses, agentes e mediadores com vários interesses, como cooperativas, empresas privadas compradoras de grãos e de comércio de insumos e o Estado" (RIBEIRO; DIAS, 2013, p. 88)

Mas essa e outras empresas acabaram fechadas por causa de dificuldades no planejamento, operacionalização, suprimento e comercialização e dentre esses motivos outros 
SANTOS, C. B. R.

A aplicação do Programa Nacional de Produção e Uso do Biodiesel na Agricultura Camponesa em Áreas de Reforma Agrária

foram aparecendo, apontando os pontos fracos do PNPB. Assim, ficava claro que o PNPB veio para gerar vantagens econômicas que não atingiram o camponês, na verdade, esse sujeito foi o alvo para conseguir tal feito, era a transformação do camponês em agricultor camponesa. O programa mesmo com o foco nas regiões menos desenvolvidas do país, sendo o Nordeste, este se concentrou nas regiões Centro -Oeste, Sudeste e Sul, regiões onde a agricultura patronal é mais forte. A soja e a gordura animal foram as matérias primas que mais obtiveram destaque, por ser também de característica da agricultura patronal, e que tem abastecido as indústrias de biocombustíveis. Dessa forma, as empresas que não fecharam, simplesmente deixaram de comprar a mamona, como aconteceu no Nordeste e passou a comprar a soja e dendê, que é mais competitivos/rentáveis (DALENOGARE, 2011). Muitos agricultores simplesmente queimaram cultivos que não fosse de soja e dendê. Isso aconteceu principalmente no Nordeste com o caso das mamonas.

\section{A política de reforma agrária}

"Muitas reformas agrárias se fizeram para dividir a terra, para torná-la de muitos, e, quem sabe, até de todas as pessoas. A democracia esbarrou nas cercas e se feriu nos arames farpados", (Betinho, 1990). Essa frase foi escolhida para iniciar nossa discussão que tem como base a Reforma Agrária, uma das políticas públicas do campo brasileiro, mas, que tornou uma dívida histórica ao povo brasileiro.

Reforma Agrária é sinônimo de sonho, uma vez que reflete a esperança de haver a distribuição das terras, o direito à terra, pois embora estejamos num país democrático, a verdade é que existe e resiste muitas injustiças que são mascaradas ou contornadas, simplesmente silenciadas.

A política de Reforma Agrária trata de um processo de re-territorialização do camponês, sabendo que este tem sido desde tempos remotos, excluído do direito da posse da terra. Como já nos dizia Fernandes (2008) nosso país possui uma política de reforma agrária ainda muito recente quando comparamos a longa história de formação dos latifúndios. Contudo o grande responsável por promover a Reforma Agrária é o Estado aliado com a luta do povo. Mas mesmo com a ampliação da luta, as ações do Estado, tem sido de pouca propriedade e amplitude. Na verdade, desde muito tempo que o Estado tem servido ou ainda é controlado pela elite Agrária. Segundo Fernandes (1999, p.01) 
SANTOS, C. B. R.

A aplicação do Programa Nacional de Produção e Uso do Biodiesel na Agricultura Camponesa em Áreas de

Reforma Agrária

A luta pela reforma agrária ganhou força com o advento das organizações políticas camponesas, principalmente, desde a década de cinquenta, com o crescimento das Ligas Camponesas. Todavia, a luta pela terra é uma política que nasceu com o latifúndio. Portanto, é fundamental distinguir a luta pela terra da luta pela reforma agrária. Primeiro, porque a luta pela terra sempre aconteceu, com ou sem projetos de reforma agrária. Segundo, porque a luta pela terra é feita pelos trabalhadores e na luta pela reforma agrária participam diferentes instituições.

A lei que sancionou a Reforma Agrária ocorreu em 1964, época em que houve maior preocupação a grande desigualdade social presente no Brasil, provocada pela concentração de terras. Com essa Lei $\mathbf{N}^{0}$ 4.504, de 30 de novembro de 1964 em vigor é proposta a distribuição de feixes de terra as pessoas mais carentes. Os assentamentos que hoje existem representam pouca terra, pela quantidade de hectares concentrados.

Tabela 01 - Evolução da Concentração da propriedade da terra no Brasil medida pelos imóveis $\mathbf{- 2 0 0 3 / 2 0 1 0}$

\begin{tabular}{|c|c|c|c|c|c|c|c|}
\hline \multirow[b]{2}{*}{ Classificação Imóveis } & \multicolumn{3}{|c|}{2003} & \multicolumn{3}{|c|}{2010} & \multirow{2}{*}{$\begin{array}{c}\text { Crescimento } \\
\text { da área por } \\
\text { setor } \\
2010 / 2003\end{array}$} \\
\hline & Número & Área (ha.) & $\begin{array}{c}\text { Pesos / } \\
\text { Área } \\
\text { Total }\end{array}$ & Número & Área (ha.) & $\begin{array}{c}\text { Pesos / } \\
\text { Área } \\
\text { Total }\end{array}$ & \\
\hline 1. Minifúndio & 2.736 .052 & 38.973 .971 & $9,30 \%$ & 3.318 .077 & 46.684 .657 & $8,20 \%$ & $19,70 \%$ \\
\hline $\begin{array}{c}\text { 2. Pequena } \\
\text { Propriedade }\end{array}$ & 1.142 .937 & 74.195 .134 & $17,70 \%$ & 1.338 .300 & 88.798 .805 & $15,50 \%$ & $19,70 \%$ \\
\hline 3. Média Propriedade & 297.220 & 88.100 .414 & $21,10 \%$ & 380.584 & 113.879 .540 & $19,90 \%$ & $29,30 \%$ \\
\hline $\begin{array}{l}\text { 4. Grande } \\
\text { Propriedade }\end{array}$ & 112.463 & 214.843.865 & $51,30 \%$ & 130.515 & 318.904.739 & $55,80 \%$ & $48,40 \%$ \\
\hline a) Improdutiva & 58.331 & 133.774 .802 & $31,90 \%$ & 69.233 & 228.508 .510 & $(40 \%)$ & $71,00 \%$ \\
\hline b) Produtiva & 54.132 & 81.069 .063 & $19,40 \%$ & 61.282 & 90.396 .229 & $(15,8 \%)$ & $11,50 \%$ \\
\hline 5. Total - Brasil & 4.290 .482 & 418.456 .641 & $100,00 \%$ & 5.181 .645 & 571.740 .919 & $100,00 \%$ & $36,60 \%$ \\
\hline
\end{tabular}

Fonte: Cadastro do INCRA - Classificação segundo dados declarados pelo proprietário e de acordo com a Lei Agrária/93

Portanto,

a reforma agrária é uma precária política de assentamentos rurais, porque grande parte dos assentamentos são frutos de regularização fundiária e não de desapropriação de terras para assentar pessoas que não tenham acesso a esta, mas concessão de títulos definitivos para posseiros que há muito tempo ocupavam essas áreas (ALENTEJANO, 2004, p. 05).

Muitos pontos foram colocados nesta Lei, mas que até hoje não foram cumpridas, como a desapropriação de terras onde ocorre exploração não racional da terra. Consta ainda no documento ser de direito, o apoio na assistência técnica aos trabalhadores rurais, mas também vê que até hoje na maioria dos assentamentos não possuem qualquer assistência, não 
SANTOS, C. B. R.

A aplicação do Programa Nacional de Produção e Uso do Biodiesel na Agricultura Camponesa em Áreas de

Reforma Agrária

tem acesso a eletricidade, água encanada, hospital, escola que são de direitos básicos a esses sujeitos.

Essa Lei de 1964 que foi citada recebeu alterações, essas alterações ocorreram ao longo do tempo, e uma das alterações mais recentes provém do ano de 2014. De modo geral, podemos dizer que além de muito do que é proposto nesta Lei não ser cumprido, temos também algumas falhas nela. Assim alguns pontos nos chamam atenção dentre eles está no artigo 73, Capítulo III da Assistência e Proteção à Economia Rural:

Dentro das diretrizes fixadas para a política de desenvolvimento rural, com o fim de prestar assistência social, técnica e fomentista e de estimular a produção agropecuária, de forma a que ela atenda não só ao consumo nacional, mas também à possibilidade de obtenção de excedentes exportáveis, serão mobilizados, entre outros, os seguintes meios:

I - Assistência técnica;

II - produção E distribuição de sementes e mudas; artificial;

III - criação, venda e distribuição de reprodutores e uso da inseminação

IV - Mecanização agrícola;

V - Cooperativismo;

VI - Assistência financeira e creditícia;

VII - assistência à comercialização;

VIII - industrialização e beneficiamento dos produtos;

IX - Eletrificação rural e obras de infraestrutura;

$\mathrm{X}$ - Seguro agrícola;

XI - educação, através de estabelecimentos agrícolas de orientação profissional;

XII - garantia de preços mínimos à produção agrícola.

$\mathrm{Na}$ verdade, são elementos que pouco existem numa unidade de assentamento. Além de que muitos dos elementos colocados acabam por danificar o ambiente e ir contra a realidade e cultura camponesa com a introdução de certos insumos que não faz parte do seu labor com a terra. Como por exemplo, em relação a assistência e comercialização que é colocado

Os órgãos referidos no artigo $73, \S 2^{\circ}$, alínea b, deverão, se necessário e quando a rede comercial se mostrar insuficiente, promover a expansão desta ou expandir seus postos de revenda para atender aos interesses de lavradores e de criadores na obtenção de mercadorias e utilidades necessárias às suas atividades rurais, de forma oportuna e econômica, visando à melhoria da produção e ao aumento da produtividade, através, entre outros, de serviços locais, para distribuição de produção própria ou revenda de:

I - Tratores, implementos agrícolas, conjuntos de irrigação e perfuração de poços, aparelhos e utensílios para pequenas indústrias de beneficiamento da produção;

II - Arames, herbicidas, inseticidas, fungicidas, rações, misturas, soros, vacinas e medicamentos para animais;

III - corretivo de solo, fertilizantes e adubos, sementes e mudas. 
SANTOS, C. B. R.

A aplicação do Programa Nacional de Produção e Uso do Biodiesel na Agricultura Camponesa em Áreas de

Reforma Agrária

A crítica está principalmente nos insumos químicos que prejudicam o solo e o alimento. Aqui percebemos que são tentativas que visam transformar o sujeito camponês naquele agricultor familiar que já foi citado anteriormente. A tecnologia é importante e deve fazer parte dos sujeitos camponeses, mas são tecnologias alternativas, e não tecnologias prejudiciais ao meio ambiente e a nós.

Percebe-se ainda que a Reforma Agrária embora seja uma política instituída em lei, essa ainda não é prioridade do Estado. O Estado prioriza o latifúndio, que hoje muda de nome, denominando de agronegócio. Contudo, embora de sua aparência ter mudado um pouco com a introdução de tecnologias e extensos monocultivos, sua essência continua a mesma. De exploração e concentração, Fernandes (2008).

Entra ano e sai ano de promessas no período de eleição. Mas o que resulta são somente promessas. A Reforma Agrária não é uma promessa de hoje, e o Estado a partir de um governo, tem acionado outras políticas de cunho principalmente econômico como providencia para calar as reivindicações dos povos e fazer prevalecer o campo de negócios!

\section{RESULTADOS E DISCUSSÕES}

Devido a produção de base camponesa não ser tão valorizada, e por muitas comunidades camponesas viverem em situação precária, desprovida de recursos principalmente financeiros, que o governo lançou o Programa Nacional de Produção e Uso de Biodiesel (PNPB) como sendo a "oportunidade" do camponês melhorar sua situação financeira inserindo-se no mercado. Na produção de biodiesel, vários cultivos foram utilizados, desde que fossem as oleaginosas. Contudo, o principal produto que tem sido valorizado e prevalecido nas unidades camponesas, desde o início da criação do programa é o cultivo de soja.

Além da agricultura camponesa ter sido escolhida como sendo o principal seguimento do PNPB, a produção da mamona recebeu destaque nesse seguimento. Mas a mamona não correspondeu a principal matéria-prima. Os principais problemas do PNPB corresponderam "a fragilidade na integração com a cadeia produtiva, os fracos incentivos efetivos no início do programa, além de ter sido inserida na aventura de produzir matéria prima sem que a cadeia produtiva estivesse devidamente estruturada" (BRAGA, 2008, p. 43). 
SANTOS, C. B. R.

A aplicação do Programa Nacional de Produção e Uso do Biodiesel na Agricultura Camponesa em Áreas de Reforma Agrária

O PNPB é mais um programa setorial e que tem o grande problema/falha de não tratar da questão agrária, ou seja, não prevê a desconcentração de terra, não valoriza/preocupa com a identidade camponesa, dando considerável ênfase na questão econômica, como forma de aliviar os problemas dos povos camponeses. A Reforma Agrária também não é uma política com enfoque territorial e o PNPB da SAF tem pouco dialogo e interação com a política de Reforma Agrária do INCRA. Na verdade, o diálogo que estabelecem e mesmo suas ações/interações são contraditórias para o fortalecimento da agricultura camponesa, mas coerentes para o fortalecimento do agronegócio no campo.

A Reforma Agrária no Brasil como já foi colocado anteriormente nunca ocorreu efetivamente, ela ocorre de maneira tímida e lentamente para ir acalmando os conflitos do campo. É uma Reforma Agrária vergonhosa, para um país tão concentrado de terras e com tantos problemas que são gerados por meio dessa concentração. Na política de Reforma Agrária, como foi discutido anteriormente, percebemos falhas quando estimula o uso de insumos químicos. Contudo, é importante saber que tal ponto encaixa diretamente com o PNPB, um programa que teve a proposta de inclusão social particularmente dos assentados, mas que materializou em outra realidade, e essa realidade que foi gerada se deve exponencialmente a dimensão econômica que foi a única considerada suficiente para interferir e sanar os problemas vivenciados por esses sujeitos.

Dentre esses problemas podemos apontar especificamente para subordinação e ou na exclusão da classe camponesa.

\footnotetext{
há momentos em que o capital ao invés de expropriar o camponês, subordina a produção deste a indústria, dominando a circulação e drenando, assim, a renda da terra camponesa. Assim, há locais em que as relações capitalistas subordinam as relações camponesas e, consequentemente, seus territórios, sendo que as técnicas e as tecnologias de produção agropecuária são determinadas pelo agronegócio que capitaliza a renda produzida pelos camponeses. Trata-se de uma territorialidade infringindo, subordinando a outra territorialidade (ROSS, 2016, p.171).
}

A subordinação quando o sujeito perde a sua autonomia do processo produtivo, passando a seguir o modelo capitalista de produção com monocultivos (soja, dendê, mamona entre outras oleaginosas incentivadas pelos PNPB) e utilização de insumos químicos. E a exclusão quando o sujeito camponês não consegue sair desse sistema de subordinação, acarretando em uma série de problemas que o leva a tomar medidas drásticas tais como a venda da terra (FERNANDES, 2008). 
SANTOS, C. B. R.

A aplicação do Programa Nacional de Produção e Uso do Biodiesel na Agricultura Camponesa em Áreas de Reforma Agrária

Portanto, nas entrelinhas da própria política de Reforma Agrária existe o incentivo em seguir o modelo capitalista de produção. Além desse fato temos um outro que não é novidade que é na sua maneira de não distribuir terras, mas de regulariza a posse destas. Para fortalecer esse contexto tem se articulado o PNPB, uma dentre tantas políticas públicas que esconde sua verdadeira intencionalidade, ao oferecer aos poucos assentados uma melhor condição financeira a partir do cultivo de oleaginosas principalmente de soja. Com o PNPB há o esforço de provocar a desterritorialização novamente desses sujeitos que a partir da luta conquistaram sua terra. O PNPB resulta

na sujeição da terra ao agronegócio, pois em todo o processo de produção, desde a compra dos insumos até os descontos referentes ao que será pago às famílias, além delas estarem sujeitas ao mercado de commodities, não há liberdade na escolha dos insumos e da assistência técnica, na venda, no preço e nos descontos que as empresas podem fazer. (RIBEIRO; DIAS 2013, p.89).

De modo mais claro, o PNPB, incentiva camponeses assentados a tornar pequenos e médios capitalistas, transformando sua propriedade em um "agronegocinho", sabendo ainda que neste modelo de produção (agronegócio) é inevitável o uso de agrotóxicos. Vemos aí a relação intrínseca dessas duas políticas que deveriam ser de desenvolvimento rural, mas conjuntamente tem provocado o agravamento social quando vemos que a Reforma Agrária ainda é distante para muitos e que o PNPB é uma ameaça reforçada, as vezes tentadora a aqueles que tem seu pedaço de chão.

Fica claro que a agricultura camponesa é só uma fachada que tem no Programa Nacional de Produção e Uso do Biodiesel. O PNPB é um desses programas responsáveis por um trágico momento para a agricultura camponesa, pois, quando foi implementado o PNPB, muitos camponeses mergulharam fundo se propondo a seguir o que era proposto. Na verdade, esses sujeitos estavam enxergando meios de melhorar economicamente e de maneira muito mais fácil. Em sua grande maioria achava ter encontrado uma condição para romper a sua exclusão.

Num país como o Brasil a implementação de políticas públicas para os e com os sujeitos camponeses tem sido um desafio, um desafio para a classe trabalhadora que vive no e do campo. O PNPB não partiu de baixo para cima, contou muito mais com o velho caráter de cima para baixo.

Todavia, esse artigo tem importante papel em relação as políticas públicas enquanto instrumentos de intervenção nos territórios, mas que está servindo prioritariamente 
SANTOS, C. B. R.

A aplicação do Programa Nacional de Produção e Uso do Biodiesel na Agricultura Camponesa em Áreas de Reforma Agrária

ao capital, principalmente no caso dos assentamentos, que são espaços de re-territorialização do campesinato. É fazer destes que foram reterritorializados, subordinados ao capital, ou de ainda simplesmente tomar o direito que conquistaram.

\section{CONSIDERAÇÕES FINAIS}

Quando os movimentos de luta pela terra estavam fortes no momento de transição do governo FHC para o governo Lula tivemos políticas e políticas para os povos do campo. Ou seja, políticas construídas para os sujeitos camponeses, e políticas com os sujeitos camponeses.

De modo geral a Reforma agrária e outras políticas públicas ganhavam um pouco mais de força no campo, mas chegou um momento em que essa força foi se amenizando de tal forma que "mantivera a estrutura agrária concentrada, criminalizando as estratégias dos movimentos que buscavam a redistribuição das terras e criação de programas, quase que exclusivamente, de assistência social e de inserção comercial" (RIBEIRO; DIAS, 2013, p. $83)$.

Boa parte das políticas públicas que foram implementadas a partir da década de 2000 para agricultura camponesa teve como viés somente a perspectiva econômica, de mercado. Tais políticas/programas tiveram como principal problema o de não perceber a realidade do sujeito, visando somente a questão econômica e levando a diminuição das áreas de produção de alimentos pela agricultura camponesa. Isso fica evidente numa Reforma Agrária pouco efetiva, sendo uma política que nas suas entrelinhas incentiva ainda o uso de insumos químicos e o PNPB que incentiva a transformação do modelo de agricultura camponesa em um mini agronegócio. Na verdade, é o estimulo ao agronegócio da agroenergia a partir do PNPB.

\section{REFERÊNCIAS}

ALBUQUERQUE, Luís Felipe. Conflitos no campo aumentam $26 \%$ e batem recorde. Brasil de Fato. Disponível em: https://www.brasildefato.com.br/2017/04/18/conflitosaumentam-e-violencia-no-campo-bate-recorde-diz-comissao-pastoral-da-terra/. Acessado em: 07/10/2017. 
ALENTEJANO, Paulo Roberto Raposo. Política de assentamentos rurais do governo FHC e os desafios da Reforma Agrária no Brasil do século XXI. AGRÁRIA, no 1, pp. 2-15, 2004.

BRAGA, Carlos Augusto Ribeiro Ferreira. Análise do Programa Nacional de Produção e Uso de Biodiesel - PNPB e o Desafio da Inclusão da Agricultura Camponesa. Monografia apresentada ao Instituto de Geografia, da Universidade Federal de Uberlândia, como requisito para obtenção da titulação de bacharel em Geografia, 2008

BRASIL. LEI No 4.504, DE 30 DE NOVEMBRO DE 1964. Disponível em: http://www.planalto.gov.br/ccivil_03/leis/L4504.htm.

BRASIL. Ministério do Desenvolvimento Agrário. Disponível em: http://www.mda.gov.br/sitemda/secretaria/saf-biodiesel/o-que-\%C3\%A9-o-programanacional-de-produ\%C3\%A7\%C3\%A3o-e-uso-do-biodiesel-pnpb. Acessado em: 07/10/2017.

DALENOGARE, Jamir Fortunato. O Programa Nacional de Produção e Uso do Biodiesel (PNPB): descaminhos entre as diretrizes e objetivos propostos e a formulação do processo produtivo atual. Monografia para obtenção do título de tecnólogo em planejamento e gestão para o desenvolvimento rural. UFRGS, 2011.

FELÍCIO, Munir Jorge; FERNANDES, Bernardo Mançano. A Conflitualidade dos Projetos de Desenvolvimento Rural a partir dos Conceitos Camponês/Agricultor Camponesa. In: Construindo um Estilo de Pensamento na Questão Agrária: o debate paradigmático e o conhecimento geográfico. Presidente Prudente, junho de 2013

FERNANDES, Bernardo Mançano. Educação do Campo e Território Camponês no Brasil. In: Por uma Educação do Campo. Incra/MDA, Brasília, 2008.

FERNANDES, Bernardo Mançano. Brasil: 500 anos da luta pela terra.

Artigo veiculado na Revista "Reforma Agrária", da Associação Brasileira de Reforma Agrária - ABRA, Volume 28 - nº 1 JAN/AGO de 1999.

FERNANDES, Bernardo Mançano; WELCH, Clifford Andrew; GONÇALVES, Elienai Constantino. Políticas Fundiárias no Brasil: Uma Análise Geo-Histórica da Governança da Terra no Brasil. In: Construindo um Estilo de Pensamento na Questão Agrária: o debate paradigmático e o conhecimento geográfico. Presidente Prudente, junho de 2013.

FERREIRA, Vicente da Rocha Soares; et al. Programa Nacional de Produção e Uso de Biodiesel (PNPB): Política Pública sustentável de geração de emprego e renda? Rio de janeiro, setembro de 2008.

INSTITUTO NACIONAL DE COLONIZAÇÃO E REFORMA AGRÁRIA INCRA. Análise da estrutura fundiária brasileira. Departamento de Análise Estatística, Brasília - DF, 2010.

JUNIA, Raquel. "Agricultores familiares não querem ser "agronegocinho". Articulação Nacional de Agroecologia. Publicado em 17 de junho de 2012. Disponível em: 
SANTOS, C. B. R.

A aplicação do Programa Nacional de Produção e Uso do Biodiesel na Agricultura Camponesa em Áreas de

Reforma Agrária

http://www.agroecologia.org.br/2012/06/17/agricultores-familiares-nao-querem-ser-

agronegocinho/. Acessado em: 07/10/17

MOLINA, Mônica Castagna. Políticas públicas. In: Dicionário da Educação do Campo. Expressão Popular. 2012.

POLINSKI, Anna Cláudia; PINTO Larissa Bastos. POLÍTICA AGRÁRIA NO BRASIL. IV Congresso Paranaense de Assistentes Sociais, 2009. Disponível em:

http://www.cresspr.org.br/site/politica-agraria-no-brasil/. Acessado em: 07/10/1993

PORTO, José Renato Sant'Anna. Desenvolvimento territorial: origens, trajetórias e sua influência nas políticas públicas de desenvolvimento rural. Novos Cadernos NAEA, v. 18, n. 1 p. 145-111. Jan. - jun., 2015.

RIBEIRO, D. D.; DIAS, S. D. Políticas públicas para a agricultura camponesa: o PAA e o PNPB. Mercator, Fortaleza, v. 12, n. 27, p. 81-91, jan. /abr. 2013. Disponível em:

<http://www.mercator.ufc.br/index.php/mercator/article/view/743>. Acesso em: 24 set. 2014.

ROSS, D. A reprodução contraditória do campesinato frente a territorialidade do agronegócio: subordinações e resistências em assentamentos rurais no Centro-Sul do Paraná. In: NERA, Presidente Prudente, v. 19., n. 30, p.169-187, jan. / abr. 2016.

SANTOS, Clarice Aparecida dos. Educação do Campo e Políticas Públicas no Brasil. A instituição de políticas públicas pelo protagonismo dos movimentos sociais do campo na luta pelo direito a educação. Dissertação de mestrado da Faculdade de Educação na UnB. 2009.

TREVISAN, Andrei Pittol and VAN BELLEN, Hans Michael. Avaliação de políticas públicas: uma revisão teórica de um campo em construção. Rev. Adm. Pública. 2008, vol.42, n.3, pp. 529-550.

Autora

Cássia Betânia Rodrigues dos Santos - Possui Graduação em Geografia pela Universidade Estadual de Goiás (UEG) e Mestrado em Meio Ambiente e Desenvolvimento Rural pela Universidade de Brasília (UnB). Atualmente é Professora de Geografia na Secretaria de Educação do Distrito Federal (GDF).

Artigo recebido em: 02 de agosto de 2016.

Artigo aceito em: 08 de outubro de 2017. 